\title{
Comparative Histoarchitectural Study of Splenic Components in Sheep and Goat
}

\author{
R. Gnanadevi, S. Senthilkumar, T.A. Kannan* and Geetha Ramesh \\ Department of Veterinary Anatomy, Madras Veterinary College, Tamil Nadu Veterinary and \\ Animal Sciences University, Chennai-07, Tamil Nadu, India \\ *Corresponding author
}

\section{Keywords}

Histo-architecture, Gross, Histology, Immunohistochemisrty, Spleen, Small Ruminants

Article Info

Accepted:

12 April 2019

Available Online:

10 May 2019

\section{A B S T R A C T}

Animal husbandry practices like sheep and goat rearing offer many advantages for beginners and also experienced farmers. They are well suited and productive for the prevailing agro-climatic conditions in India. In mammals, health status is governed by the organ of lymphatic system. Though spleen is the secondary lymphatic organ, it is the largest among the lymphoid organs which plays a crucial role in immune function. For the present study, splenic tissue from adult sheep and goat (6 Nos. each) were collected from Corporation slaughter house, Chennai. Gross, microscopic and immunohistochemical observations were done. Micrometric observations of various structures were also recorded. The spleen of sheep was triangular, whereas, in goat it was roughly quadrangular in outline. In both the species, parenchyma was covered by a thick capsule, predominantly made up of collagen, elastic and smooth muscle fibres. Thickness of capsule in sheep was $150 \pm 10.33 \mu$ and in goat it was $141 \pm 11.5 \mu$. Trabeculae originated from inner side of the capsule and extended in to parenchyma in both the species. Parenchyma was made up of white pulp and red pulp and the proportion of these were almost equal. The white pulp was composed of splenic nodule and peri-arterial lymphatic sheath. Red pulp was compost of irregular splenic cords separated by splenic sinusoids. Immunohistochemical localization of T-lymphocytes revealed the distribution of T-lymphocytes around the PALS and also scattered in the red pulp.

\section{Introduction}

In India, small ruminants like sheep and goat plays a very important role in the food and nutritional security of landless, marginal and small farmers in all Agro-climatic zones. Sheep and goat is the main meat-producing animal in India. Apart from meat, they also produced variety of products viz. milk, skin, wool and manure (Shalander kumar and Roy, 2013).
In both, mammals and birds, it is well understood that lymphatic tissue plays an important role in defense mechanism against microorganism (Suri et al., 2017). Spleen is the largest and major secondary lymphatic organ which is involved in filtration of blood and preserves iron for hemoglobin synthesis (Samuelson, 2007). It also plays an important role in destruction of RBCs, phagocytosis and antigen-antibody interactions (Kannan et al, 2017). In order to perform these important 
functions, splenic parenchyma possesses an unique parenchyma and supported by stromal tissue (Onkar and Govardhan, 2013).

Comparative anatomy helps to show how an organism functions, how they develop and how they are linked by evolution, the process by which organism changes over many generations (Kardong, 2011). Considering the economic importance of small ruminants in India and their potential immunological role of spleen, the present study is aimed to compare the histological structure of spleen of sheep and goat.

\section{Materials and Methods}

Splenic tissues for this study were collected from adult animal brought for slaughter at Corporation slaughter house, Chennai (Sheep samples-6, Goat samples-6). The animals were apparently healthy and did not show any clinical signs of disease. Immediately after collection, each sample was brought to the Department of Veterinary Anatomy, Madras Veterinary College, Chennai. The samples were washed gently in tap water to remove blood and blood clots. Then the samples were fixed in $10 \%$ Neutral Buffered Formalin solution and processed for routine paraffin sectioning. The sections were stained with Hematoxylin and Eosin, Masson's trichrome and Gomori's method for reticular fibres (Bancroft and Stevens, 2013).

For $\mathrm{T}$ lymphocytes localization, the sections were processed through xylol and alcohol solution and heat mediated antigen retrieval was done using TRIS-ED buffer $(\mathrm{pH} 8.5$ to 9.0). Blocking of endogenous peroxide was done with $3 \%$ hydrogen peroxide stained with CD3 ready to use primary antibody (Pathn Situ co.) for 30 to 45 minutes in a moist chamber. Then the section were incubated with ready to use polyexcel HRP (Pathn Situ co.) for $12 \mathrm{~min}$. DAB chromogen (1 ml DAV buffer + One drop DAB chromogen) for 2 to 5 minutes was used to make antigen-antibody reaction visible. Gill's hematoxylin was used for counterstaining (Kannan et al., 2019).

Microscopic observations were done with Leica microscope (CH9435 Heer brugg) under different magnifications. Micrometric observations viz., capsule and trabecular thickness, diameter of lymphatic nodule and germinal centre and number of lymphatic nodules per field under $5 \mathrm{x}$ were measured using Leica Applications Suite V 4.4 software (Kannan et al., 2019). The data were analysed using SPSS software to calculate mean and standard error (Bhargavi et al., 2019).

\section{Results and Discussion}

\section{Gross morphology}

In the present study, in both sheep and goat, spleen consisted of two surfaces viz., parietal and visceral. The parietal surface was convex were as, visceral surface was concave and showed hilus at the dorsal end of the cranial border as per Nickel et al., (1979). In sheep, it was triangular where as roughly quadrangular in outline with blunt edges incase of goats. A similar finding was observed by (Suri et al., 2017).

\section{Histomorphometry}

\section{Capsule}

In both sheep and goat, the parenchyma was covered by a thick capsule, composed of fibro-elastic and muscular capsule, as reported by (Devi et al., 2016). It was predominantly made of collagen fibres with elastic and smooth muscle fibres (Figure 1). Thickness of the capsule varied between sheep and goat (Table 1). Thickness of the capsule was slightly higher in Sheep (150 \pm $10.33 \mu)$ when compared to goat $(141 \pm 11.15$ 
$\mu)$. Whereas, the capsular thickness of sheep was $150 \pm 8.14 \mu$ and in goat it was observed as $282.27 \pm 14.88 \mu$ in Suri et al., (2017) and Khalel (2010) reported that the capsular thickness of Awasi sheep was $140.5 \pm 13.712 \mu$ and Alim et al (2012) reported capsular thickness of $251.44 \pm 12.56 \mu$ in goat.

Trabeculae originated from the inner side of the capsule, extended into the parenchyma, in both species. It was composed predominantly of smooth muscle fibres along with collagen and elastic fibres (Figure 2) (Usende et al., 2014). Presence of sub-capsular and peritrabecular sinuses lined by endothelium were also observed as per Zidan et al., (2000).

Thickness of trabeculae varied between sheep and goat (Table 1), however, there was no significant difference. In contrast, Suri et al., (2017) reported that the thickness of trabeculae in goat $(224.67 \pm 20.19 \mu)$ was significantly higher than in sheep (104.35 \pm $8.92 \mu)$.

In addition to collagen and smooth muscle fibres, reticular fibres were also observed in the capsule and trabeculae in both the species (Figure 3). These fibres also extended into the trabeculae and were arranged parallel to collagen, elastic and smooth muscle fibres (Devi et al., 2016). The presence of smooth muscle and elastic fibres in the capsule and trabeculae might help in changing the volume of spleen and pumping out excess blood in circulation (Banks, 1981).

\section{Parenchyma}

Histoarchitecture of the parenchyma in both sheep and goat was found to be similar. It was composed of white pulp and red pulp and the proportion of these were almost equal which indicated that the spleen of ruminants belongs to intermediate type, contrast to storage and defensive type in other domestic animals as per Fishbeck and Sibastiani (2008). In both the species, a clear demarcation between white pulp and red pulp was observed (Figure 4).

The white pulp of spleen was composed of spleenic nodule and peri-arterial lymphatic sheath (PALS) distributed among the red pulp. The splenic lymphatic nodules were almost circular in outline composed of germinal centre at the centre and were surrounded by marginal zone (Figure 5) as per Banks (1993). The germinal centre was paler, composed of larger sized lymphocytes and lymphoblast. The nucleus showed heterochromatin (Figure 6). Marginal zone was slightly darker and composed of numerous small sized lymphocytes (Figure 6) as par Devi et al., (2016). The central artery or nodular arteriole occupied the paracentral position in the nodule. This is in accordance with the findings of Trautman and Fiebiger (1957) in domestic animals. Number of nodules per field under $5 \mathrm{x}$ was found to be almost similar in both sheep $(1.90 \pm 2.40)$ and

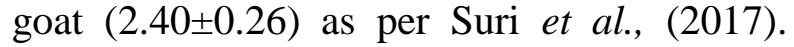
This indicated that both the species had equal proportion of white pulp.

Periarterial lymphatic sheath were observed as diffuse lymphatic sheath adjacent to the central artery. It was composed of closely packed small lymphocytes and several medium to large sized lymphocytes and reticular cells (Figure 7). Few macrophages and plasma cells were also observed at the periphery of periarterial lymphatic sheath as reported by Sasou and Sugai (1992).

The regions between the white pulp and trabeculae constituted the red pulp. It was composed of irregular splenic cords separated by splenic sinuses (Figure 8 ). The cords were composed of lymphocytes of varied size and reticular cells as reported by Khalel (2010) in domestic animals (Figure 9). The arterioles 
from the periphery of the white pulp observed to enter the red pulp as sheathed capillaries. These capillaries were found to be surrounded by reticular cells and macrophages formed the ellipsoids.

Table.1 Mean \pm SE of various parameters in sheep and goat spleen

\begin{tabular}{|l|c|l|l|}
\hline \multirow{2}{*}{ Parameters } & \multicolumn{2}{|c|}{ Mean \pm SE } & \multirow{2}{*}{ t-value } \\
\cline { 2 - 3 } & Sheep & Goat & \\
\hline Capsule thickness $(\boldsymbol{\mu})$ & $150 \pm 10.33$ & $141 \pm 11.15$ & $0.562^{\mathrm{NS}}$ \\
\hline Trabeculae thickness $(\boldsymbol{\mu})$ & $134 \pm 12.06$ & $105 \pm 9.79$ & $0.076^{\mathrm{NS}}$ \\
\hline White pulp diameter $(\boldsymbol{\mu})$ & $456 \pm 14.31$ & $501 \pm 32.81$ & $0.231^{\mathrm{NS}}$ \\
\hline $\begin{array}{l}\text { Germinal center } \\
\text { diameter }(\boldsymbol{\mu})\end{array}$ & $244 \pm 12.27$ & $323 \pm 24.63$ & $0.010^{*}$ \\
\hline Number of nodules $(\mathbf{5 x})$ & $1.90 \pm 0.23$ & $2.40 \pm 0.26$ & $0.175^{\mathrm{NS}}$ \\
\hline
\end{tabular}

NS - No significant difference between sheep and goat $(\mathrm{P}>0.05)$

* - Significant difference between sheep and goat $(\mathrm{P}<0.05)$

Fig.1 Photomicrograph of sheep (a) and goat (b) spleen showing the distribution of collagen (blue) and smooth muscle fibres (red)
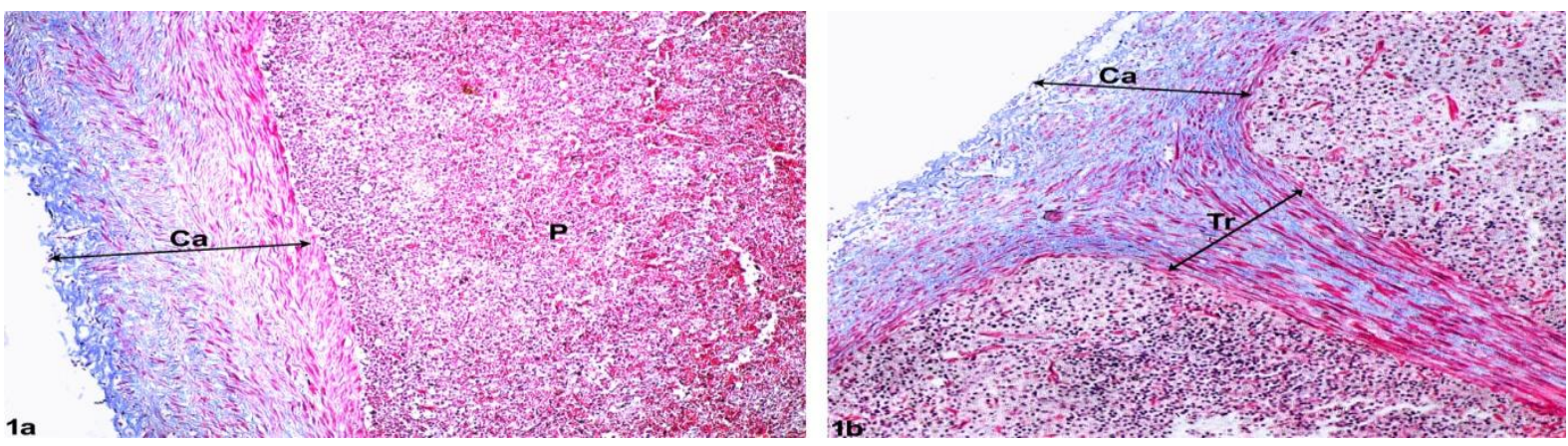

Fig.2 Spleenic trabeculae of sheep (a x 400) and goat (a x 100) showing predominant smooth muscle fibers (red) along with collagen (blue) Masson's Trichrome

$\mathrm{Ca}-$ Capsule $\quad \mathrm{P}$ - Parenchyma $\quad \mathrm{Tr}-$ Trabecula $\quad$ Masson's Trichrome x 100
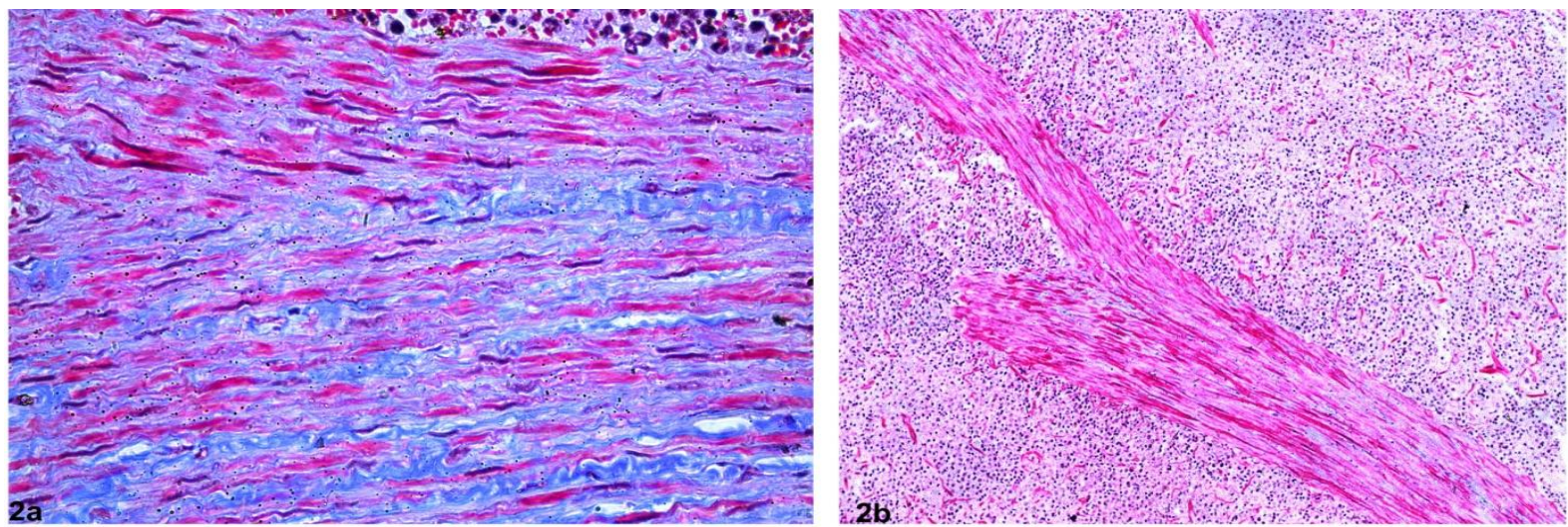
Fig.3 Photomicrograph showing the distribution of reticular fibres (arrows) in sheep and goat spleen (a \& b) Gomori's method x 100
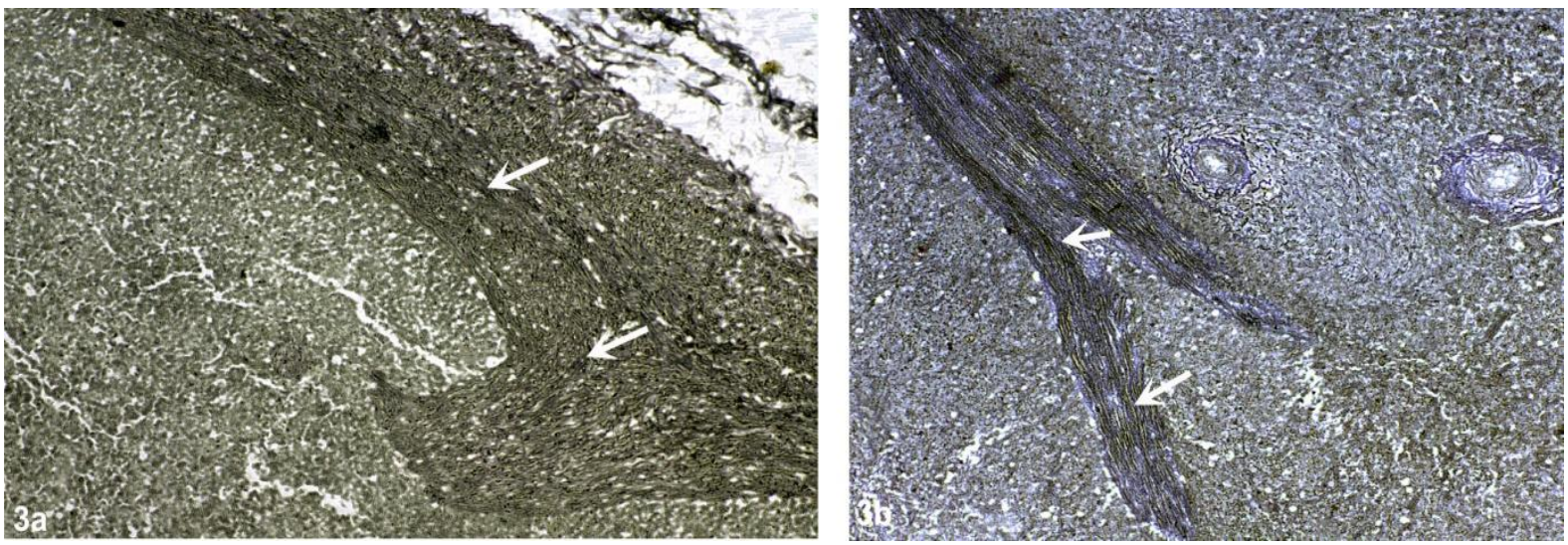

Fig.4 Photomicrograph of splenic parenchyma showing the distribution of white pulp (W) and red pulp (R) in goat spleen $\mathrm{H} \& \mathrm{E} x 12.5$

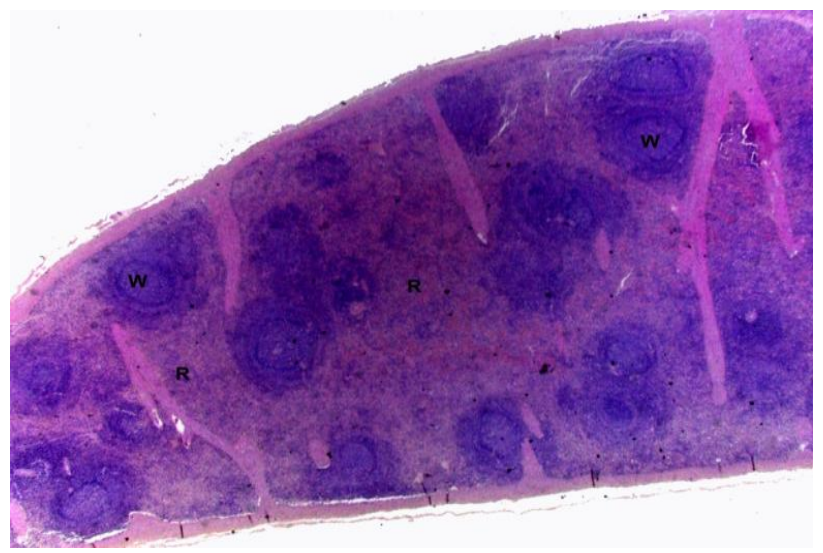

Fig.5 Photomicrograph of white pulp in spleen of sheep and goat ( $\mathrm{a} \& \mathrm{~b}$ ) $\mathrm{N}$ - Nodule PALS - Peri-arteriolar lymphatic sheath CA - Central artery H \& E x 100
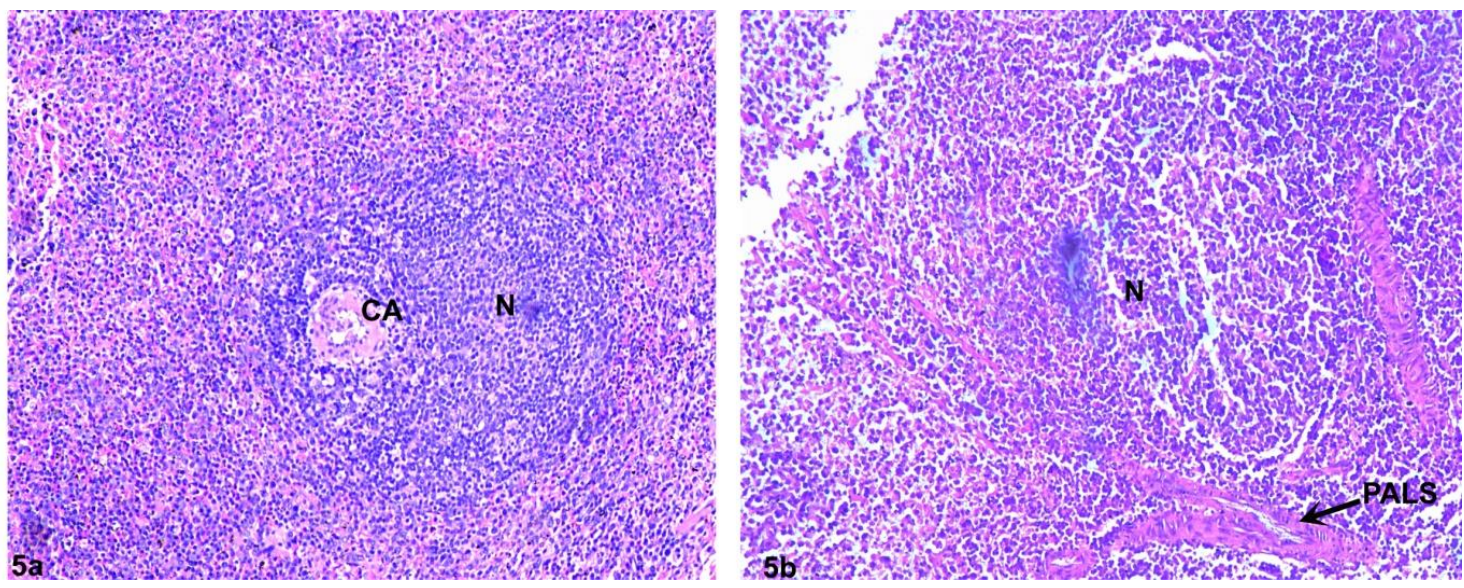
Fig.6 Photomicrograph showing the cellular components of splenic nodule in sheep spleen Lb: Lymphoblast Ll: Large lymphocyte Ls: Small lymphocytes H \& E x 400

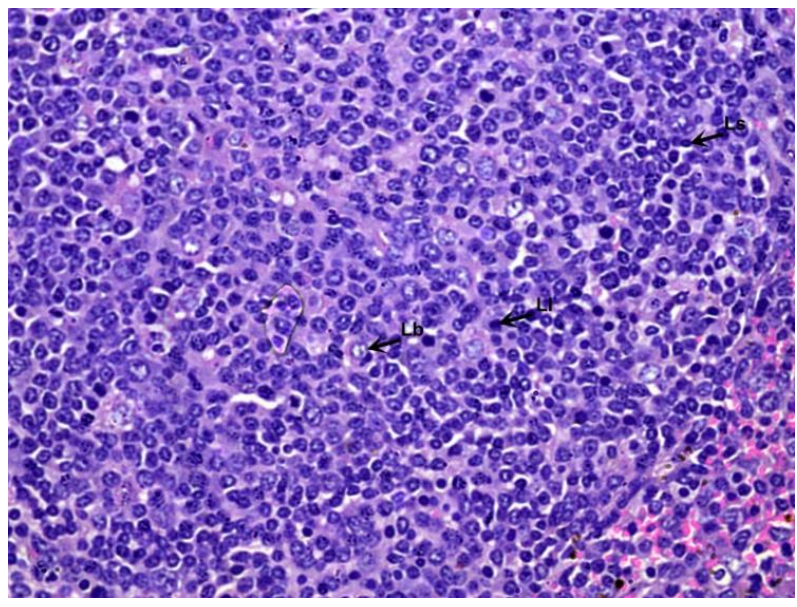

Fig.7 Photomicrograph of Peri-arteriolar lymphatic sheath in sheep and goat (a\&b) spleen H \& E $\mathrm{x} 400$
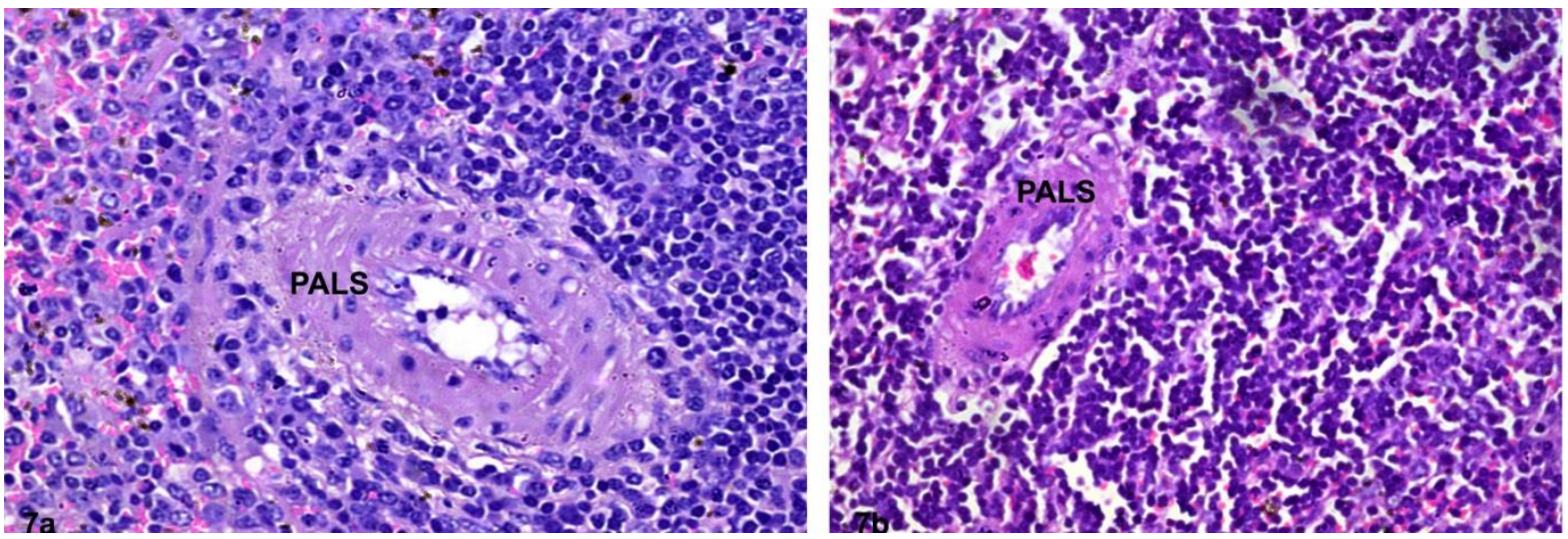

Fig.8 Photomicrograph of goat splenic red pulp

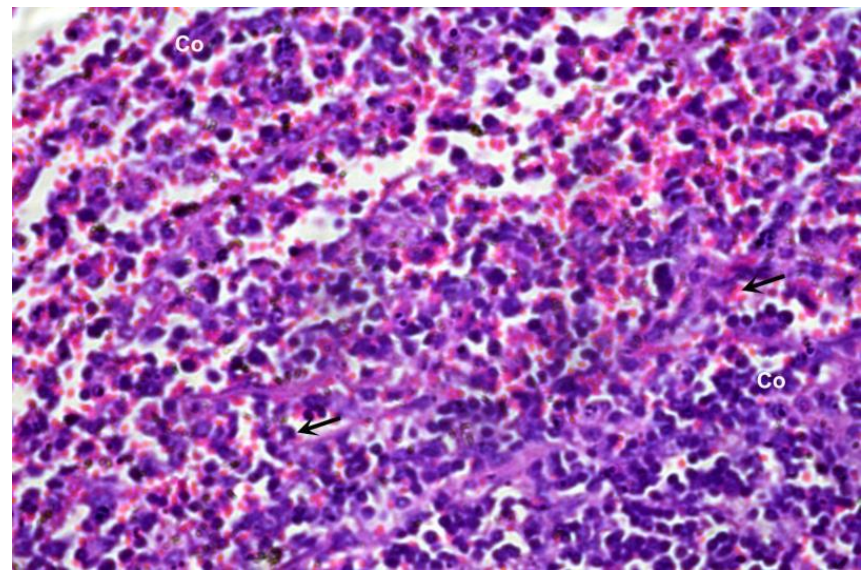


Fig.9 Photomicrograph showing the distribution of T-lymphocytes (arrows) in spleen of sheep and goat (a x $100 \&$ b x 400) IHC (DAB)

Co - Spleenic cords

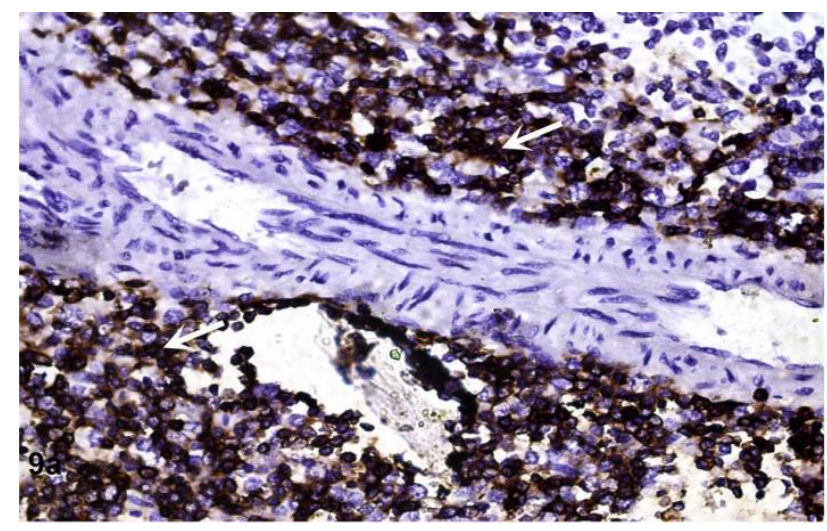

Sinusoids (arrows) $\quad$ H \& E x 400
Immunohistochemical localization of $\mathrm{T}$ lymphocytes revealed distribution of $\mathrm{T}$ lymphocyte, in the marginal zone of PALS and also in red pulp (Figure 9) in both Sheep and Goat which is in accordance with Zidan et al (2000) in one humped camel.

\section{Acknowledgement}

The author acknowledges the Dean, Madras Veterinary College and the authorities of Tamil Nadu Veterinary and Animal Sciences University, Chennai for providing necessary facilities to carry out the research work.

\section{References}

Alim, A., A.S.M. Nurunnabi, S. Ara, S. Mahbub and L.C. Mohanta. 2012. Comparative histological study on the spleen of human (Homo sapiens), cow (Bos indicus) and goat (Capra hircus). Nepal J Med Sci. 1(2): 64-67.

Bancroft, J.D. and A. Stevens, 2013. Theory and Practice of histological techniques. Churchill Livingstone, London.

Banks W.J. 1993. Applied Veterinary Histology. 3rd edn. Mosby Year Book St. Louis, USA. Pp. 283-289.

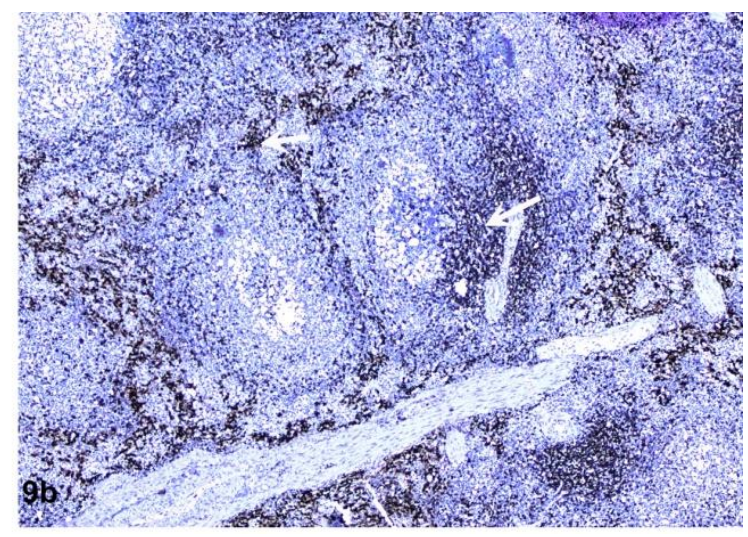

Banks, W.J., 1981. Applied Veterinary Histology. Williams and Wilkins, Baltimore/London. 327-339.

Bhargavi, S., Kannan TA, Geetha Ramesh, Sumathi D, Arun Prasad A. 2019. Radiographic Evaluation of Heart Using VHS method in Rajapalayam Dog- Indigenous Breed of Tamil Nadu. Int. J Curr. Microbiol. App. Sci. 8(02):1216-1220.

Devi, H., Mathur R and Joshi S, 2016. Histological studies on the spleen of Marwari goat (Capra hircus). Veterinary Practitioner. 17(2).

Fishbeck, DW., Sibastiani A. 2008. Comparative anatomy: manual of vertebrate dissection. 2nd ed. London: Morton Publishing Company.

Kardong, K., Vertebrates: comparative anatomy, function, evolution. 6th ed. New York: McGraw-Hill; 2011.

Khalel, EM., 2010. Anatomical and histological study of the spleen in Iraqi sheep (Awasi sheep). Bas J Vet Res. 10(2): 163-171.

Nickle, R., Schummer. A, Seiferle.E, 1979. The viscera of the domestic mammals. Springer-Verlag, Berlin Heidelberg.

Onkar, DP., Govardhan SA. 2013. Comparative histology of human and 
dog spleen. J Morphological Sci. 30(1): 16-20.

Suri, S., J.S. Sasan, K.Sarma and D. Chakraborty. 2017. Comparative gross and histomorphological studies on the spleen of sheep and goat of Jammu region of India. Explor Anim Med Res. 7(2): 179-183

Samuelson, DA., 2007. Textbook of Veterinary Histology. Missouri: Saunders Elsevier. Pp. 261-268.

Sasou, S., and Sugai T, 1992. Periarterial lymphoid sheath in the rat spleen a light, transmission and scanning electron microscopic study. The anatomical record. 232:15-24.

Shalander Kumar and M.M. Roy, 2013. Small Ruminant's Role in Sustaining Rural Livelihoods in Arid and Semiarid Regions and their Potential for Commercialization. Text book on New paradigms in livestock production from traditional to commercial farming and beyond. 2013 Edn., Agrotech Publishing academy, Udaipur, Pp: 57-80.

Kannan, T.A., Geetha Ramesh, S. Ushakumari, G. Dhinakarraj and S. Vairamuthu. 2017. Age related changes in $\mathrm{T}$ cell subsets in thymus and spleen of layer chicken (Gallus domesticus). Int.J.Curr.Microbiol. and App. Sci., 6(1): 15-19.

Thandavan Arthanari Kannan, R. Gnanadevi, S. Senthilkumar and Geetha Ramesh. 2019. Histomorphometric and immunohistochemical details of hemal nodes in Indian buffalo. Journal of entomology and zoology studies. 7(2): 384-387.

Trautmann, A., and Fiebiger, J. 1957. Fundamentals of histology of domestic animals. Translated and revised by Hable, R.E. and Biberstein, E.L. Comstock Publishing Associates, Ithaca, New York.129-135.

Usende IL., Okafor CL, Aina OO, Onyiche TE, Durotoye TI, Omonuwa AO, Jarikre TA, Maina MM and Falohun OO., 2014. Comparative studies and clinical significance of the spleens of Nigerian indigenous pig (Sus scrofa) and goat (Capra hircus). J Vet Adv. 4(7): 604-612.

Zidan M., Kassem A, Dougbag A, Ghazzawi EE, Aziz MAE and Pabst R., 2000. The spleen of the one humped camel (Camelus dromedarius) has a unique histological structure. J Anat. 196: 425 -432 .

\section{How to cite this article:}

Gnanadevi, R., S. Senthilkumar, T.A. Kannan and Geetha Ramesh. 2019. Comparative Histoarchitectural Study of Splenic Components in Sheep and Goat. Int.J.Curr.Microbiol.App.Sci. 8(05): 1387-1394. doi: https://doi.org/10.20546/ijcmas.2019.805.158 